\author{
국내 홀스타인종 젖소의 선형형질의 점수제 분석 \\ 최태정*·조광현*·이기환*·상병찬** \\ 농촌진흥청 국립축산과학원*, 충남대학교 낙농학과**
}

\title{
Analysis for Linear Type Classification Scheme on Holstein Cows in Korea
}

\author{
Te Jeong Choi*, Kwang Hyun Cho*, Ki Hwan Lee* and Byeong Chan Sang** \\ National Institute of Animal Science, R.D.A*, \\ Dept. of Dairy Science Chungnam National University**
}

\begin{abstract}
Complement of test standard, evaluation methods and models are needed to improve national competitiveness and to exchange superior genetic resources through the comparison of genetic evaluation score among nations in dairy cattle. Therefore, this study was conducted for the application of international standard to Korea considering domestic circumstance by changing linearclassification test score system of 50 classes which is currently used in Korea to system of 9 classes which is used in advanced nations of dairy. 15,230 of holstein cow linear type records with first parity records for the fifteen linear type and one total score from 2001 to 2006 and pedigree data which were collected by the Korean Animal Improvement Association were used in this study. Population classified by 9 levels was more normal distributed than 50 levels. Correlation coefficients between 50 and 9 score system showed over 0.98 by each classification scheme. Therefore, the 50 point system can be substituted with 9 point system due to their highly positive correlation. However, scores in all traits were still very contingent on classifier under the 9 point system $(\mathrm{p}<0.001)$, and $\mathrm{F}$ values between foot angle and front teat attachment showed high fluctuation depending on classifier. It means that subjective opinions of classifier would influence on linear type score as ever even if class scheme transformed to system of 9 class. Therefore, the relevance of transformation to the 9 point system should be assessed after analyses about various environmental factors.
\end{abstract}

(Key words : Linear type traits, Classification scheme, Conformation, Holstein cow)

I. 서 론

최근 젖소산유능력은 과거 10 년간 유량 연간 개량량이 $182.9 \mathrm{~kg}$ 으로 괄목할만한 증가를 하였으나 (젖소유전능력평 가보고서, 2007), 경제적 수명에 도달하지 못한 채 도태되 고 있는 실정으로 고능력우가 장수하여 생애산유량을 증 대시키는 것에 대한 관심이 점차 높아지고 있다. 따라서, 젖소의 경제수명을 늘려 생애산유량을 증대시키기 위해서 는 젖소의 신체적 기능과 밀접한 연관을 갖고 있는 기능 적 체형형질의 개량이 무엇보다도 중요하다고 할 수 있다 (Brotherstone, 1991; 이 등, 2006). 이러한 이유로 현재 젖 소에 대한 선형형질의 심사는 이미 여러 낙농국가들에서 실시되고 있으며 그 평가 기록은 장수성 (Brotherstone and Hill, 1991; Vollema and Groen, 1997; Weigel 등, 1998; Setati 등, 2004; Tsuruta 등, 2005; Neuenschwander 등, 2005; Vacek 등, 2006), 체중 (Veerkamp and Brotherstone, 1997;
Koenen and Groen, 1998), 유방의 건강 (Thomas 등, 1984; De Jong and Lansbergen, 1996), 발굽관련 문제 (Boelling and Pollott, 1998), 그리고, 분만의 용이성 (Dadati 등, 1985; Cue 등, 1990) 등을 예측하는데 중요하게 이용되어져 왔 다. 국내에서도 선형형질에 대한 자료의 수집 및 심사와 유전능력평가가 꾸준히 이루어지고 있으며 국내 젖소의 육종계획의 수립 시에 이를 활용하고 있다. 우리나라의 젖소 검정두수는 2006년 말 기준으로 20만두에 다가서고 있으며 농가와 유관기관의 꾸준한 혈통관리로 혈통비율도 2006년 50\%를 상회하여 유전능력평가를 하는데 정확도 측면에서 꾸준히 증가해왔다. 그러나 국제간의 유전평가 인 MACE (Multiply Across Country Evaluation)를 통한 우 리의 우수유전자원이 교류되기까지는 검정기준, 평가방법 과 모델 등에 있어 많은 보완이 필요하다. 또한, 이를 통 하여 경쟁력 있는 젖소를 개량하기 위해서는 낙농선진국 에서 채택하고 있는 국제기준 방법들을 현실에 맞게 적용

Corresponding author : Kwang Hyun Cho, National Institute of Animal Science, San 9, Eryong-ri, Seonghwan-eup, Cheonan-si, Chungcheongnam-do, 330-801, Ref. of Korea.

Tel: +82-41-580-3358, Fax: +82-41-580-3362, E-mail: ckh1219@rda.go.kr 
해야 하는 노력이 필요하다. 일본의 경우 2000 년에 체형 의 국제간 유전평가의 정확도 향상을 위해 선형식 체형심 사의 평가수치를 1 9단계로 변경하여 적용하고 있으며 (일본 가축개량사업국, 2002), 캐나다, 덴마크, 뉴질랜드 등 의 낙농선진국이 속한 WHFF (World Holstein Friesian Federation)에서도 9단계의 선형심사에 의한 체형심사가 실 시되고 있다. 이러한 9단계 선형심사의 도입은 선형형질 에 관한 유전평가치의 국제간 비교시에 그 정확도를 상당 히 향상시킬 수 있을 것이라고 기대된다. 따라서, 우리나 라도 국제가축기록위원회 (International Committee for Animal Recording, ICAR)에서 추천하고 있는 국제표준 평가방법 (e.g., Hewitt, 2000)에 맞추어 9단계로 변경하는 것을 적극 검토해봐야 한다. 이를 위해 본 연구에서는 점수 변경시 에 심사자에 따른 선형형질에 대한 심사점수의 변이의 차 이를 파악하고 분산분석 및 상관분석을 통해 타당성을 검 토하여 점수제 변환을 국내 현실에 맞게 적용하기 위해 실시하였다. 또한, 50 단계 심사점수와 변환된 9단계의 선 형심사점수에 영향을 미치는 심사자, 심사시의 연령 그리 고, 비유단계와 같은 환경효과에 대한 분석과 검토를 추 가적으로 수행하였다.

\section{ㅍ. 재료 및 방법}

\section{1. 공시재료}

본 연구에는 한국종축개량협회 (KAIA)가 보유하고 있는 젖소에 대한 혈통기록과 2001년부터 2006년도까지 실시한 선형심사 기록 중 최종점수(final scores) 및 15 개 선형형 질에 대해 초산차 기록을 갖는 150,230 두의 암소 선형심 사기록 자료가 분석에 이용되었다. 선형심사 형질들은 심 사자에 의해 1 50점수 단계의 범위에서 점수화되었으며 점수부여 기준은 미국홀스타인협회의 표준평가방법 (Thompson 등, 1981; Holstein Association USA, 2005)이 적 용되었다. 선형형질은 현행의 50점제의 구분에서 국제가 축기록위원회 (ICAR)에서 채택하고 있는 국제표준 평가방 법을 근거로 Table 1과 같이 9점제로 변환하였다. 그리고, 심사자는 4명, 심사연령 (age at classification)은 4단계로, 비유단계 (lactation stage)는 12단계로 구분하여 나누어 선 형 통계분석 모형에 적용하였다.

\section{2. 통계 분석 방법}

\section{(1) 자료교정}

유효자료의 선정을 위해 젓소의 생년월일, 심사일, 등록 번호, 심사일 당시 개체의 연령, 심사자 및 선형형질별 점 수에 대한 이상치를 제거한 뒤 한 개체가 2 개 이상의 자 료를 가졌을 경우에는 마지막 심사일에 해당하는 자료를 사용하였으며, 심사자의 심사 빈도가 매우 낮고 심사자를 알 수 없는 자료를 제거하였다. 농가, 심사년도, 심사자별
Table 1. A calculating table between 50 and 9 point system

\begin{tabular}{rlr}
\hline 50 point & system & 9 point \\
\hline \hline 1 & $\sim 7$ & 1 \\
8 & $\sim 12$ & 2 \\
13 & $\sim 17$ & 3 \\
18 & $\sim 22$ & 4 \\
23 & $\sim 27$ & 5 \\
28 & $\sim 32$ & 6 \\
33 & $\sim 37$ & 7 \\
38 & $\sim 42$ & 8 \\
43 & $\sim 50$ & 9
\end{tabular}

관측수가 5 이상인 개체의 심사기록만을 이용하였고, 심 사시의 연령 (age at classification)은 월령으로 바꾼 뒤 정 규성 검정에 따라 15 개월령 미만과 80 개월령을 초과하는 성적은 분석에서 제외하였고, 2 세 이하에서 5 세 이상까지 총 4단계로 나누어 분석에 이용하였다. 분만 후 비유단계 (lactation of stage)는 1 개월 단위로 총 12 수준으로 분류하 여 분석 모형에 적용하였다.

(2) 환경요인의 효과 분석

심사점수에 대한 심사자, 심사시의 연령 및 비유단계의 요인의 효과를 알아보기 위해 다변량분산분석방법 (multivariate analysis of variance) 이용하여 분석을 실시하였으며 분산분석을 위한 선형모형은 (1)과 같다. 분석은 SAS package 9.1 버전을 이용하였고, PROC GLM 절차에서 제 공되는 4가지 제곱합 중 TYPE III 제곱합을 이용하였다. 최소자승평균치 $(\mathrm{LSM})$ 간 유의성 검정을 위해 다음과 같은 귀무가설을 유의수준 $5 \%$ 로 각 형질에 대한 검정을 실시 하였다.

$$
H_{0}: \operatorname{LSM}(i)=\operatorname{LSM}(j)
$$

여기서, LSM(i(j)) : i(j)번째 효과의 최소자승평균치 $(\mathrm{i} \neq \mathrm{j})$ 이다.

$Y_{i j k}=\mu+$ classifier $_{i}+$ age $_{j}+$ stage $_{k}+e_{i j k}$

여기서,

$Y_{i j k}=\mathrm{i}$ 번째 심사자의 $\mathrm{j}$ 번째 연령에 대한 $\mathrm{k}$ 번째 비유 단계의 선형심사점수

$\mu=$ 전체평균

$h y c_{i}=\mathrm{i}$ 번째 심사자의 고정효과: 4 개

$a g e_{j}=\mathrm{j}$ 번째 연령의 고정효과 : 4개

stage $_{k}=\mathrm{k}$ 번째 비유단계의 고정효과 : 12 개

$e_{i j k}=$ 각 개체에 미치는 잔차효과 
50점제에서 9점제로 점수변환한 후 두 가지 점수 간의 상관분석은 다음의 공식에 의거하여 SAS package의 PROC CORR 절차를 이용하여 분석 하였다.

$$
r_{X Y}=\frac{\frac{1}{n} \sum\left(x_{i}-\bar{X}\right)\left(y_{i}-\bar{Y}\right)}{\sqrt{\left(\frac{1}{n} \sum\left(x_{i}-\bar{X}\right)^{2}\right)\left(\frac{1}{n} \sum\left(y_{i}-\bar{Y}\right)^{2}\right)}}
$$

\section{III. 결 과}

\section{1. 자료 분포 특성}

Table 2의 자료는 50점제 심사점수를 9점제로 변환한 자료에 대한 기초통계량과 유전력을 나타낸 것이다. 변환 된 점수는 1 에서 9점의 범위를 나타냈으며 유방의 깊이 (UD)의 경우 표준편차가 1.63 으로 다른 형질들에 비해 높 게 나타나 자료의 변이가 크게 나타났다. 체격을 나타내 는 일반외모 형질 중 키 $(\mathrm{ST})$ 의 점수가 $5.48 \pm 1.56$ 로 가장 높게 평가되었고, 반면 강건성은 $3.53 \pm 1.29$ 로 가장 낮은 평가점수를 보였다. 유방관련 형질 중에서는 유방의 깊이 (UD)가 $4.13 \pm 1.63$ 로 가장 높은 점수를 보였으며, 앞유두 의 배열위치 $(\mathrm{FTP})$ 가 $3.60 \pm 1.35$ 로 가장 낮은 평가를 받은 것으로 나타났다. 유전력 (heritability)에 있어서는 키, 엉덩 이 기울기 $(\mathrm{RA})$, 예각성 $(\mathrm{DF})$, 옆에서 본 뒷다리 (RLSV)가 각각 $0.42,0.37,0.33,0.32$ 로서 비교적 높은 유전력을 보
이고 있고 유방관련 형질들 또한, $0.23 \sim 0.29$ 의 높은 유전 력을 보이고 있어 중요한 형질임을 알 수 있었다. 반면 발굽기울기 $(\mathrm{FA})$ 는 모든 형질들 중에서 0.15 로서 가장 낮 은 유전력을 나타냈다.

각 형질별 50점제 집단의 분포특성과 변환시킨 9점제 집단의 분포특성은 Fig. 1과 같이 키 (stature)와 옆에서 본 뒷다리 (RLSV) 등이 50단계 분포보다 변환된 9단계 자료 의 분포가 더욱 정규성을 띄고 있었으며, 50 단계에서는 점수대별로 분포의 폭이 작게 나타났다. 이는 50 단계의 심사제도에서 심사자간에 선호하는 점수대의 점수 편차가 크게 나타나기 때문이었으며, 결국 특정 선호점수에 집중 되고 그 전후의 점수의 빈도가 극단적으로 감소하는 경향 을 보이는 것으로 나타났다. 이 결과는 50 단계를 사용한 선형심사에서 선형점수의 모든 부분을 유용하게 이용하고 있지 않다는 것을 보여주는 것이다. 비록 점수대 구분의 추정값은 세분화 할수록 더 정확하게 나오는 이치로 점수 폭을 줄이는 것이 문제점이 될 수 있으나 선호 심사대에 대한 분포가 아닌 정규성을 갖는 분포로 만들기 위해서는 9단계로 전환이 바람직하다고 판단된다. 이로써 9단계로 의 변경은 50 단계로 심사해온 방법에서 경계에 위치한 기 준의 주관적인 개입이 감소할 것으로 예측되며, 9단계 점 수제를 이용함으로써 정규분포에 근거한 폭넓고 공정한 평가가 이루어져 유전력의 저하를 해결하는 기능을 가질 것으로 사료된다. 결과적으로 젖소에 대한 선형심사시 심 사자의 넓은 점수영역대로 인한 부담을 감소시켜 효율적 인 선형심사가 이루어 질 것으로 판단된다.

Table 2. Basic statistic and heritability for linear traits transformed by 9 class

\begin{tabular}{lccc}
\hline \multicolumn{1}{c}{ Traits } & $\mathrm{N}$ & Mean \pm SD & Heritability* \\
\hline \hline Stature (ST) & 149,811 & $5.48 \pm 1.56$ & 0.42 \\
Strength (STR) & 147,849 & $3.53 \pm 1.29$ & 0.31 \\
Rump angle (RA) & 148,945 & $3.91 \pm 1.35$ & 0.37 \\
Thurl width (TW) & 149,645 & $3.88 \pm 1.27$ & 0.29 \\
Dairy form (DF) & 149,165 & $4.47 \pm 1.52$ & 0.33 \\
Body depth (BD) & 149,414 & $3.97 \pm 1.35$ & 0.26 \\
Rear legs side view (RLSV) & 150,230 & $4.86 \pm 1.29$ & 0.32 \\
\hline Foot angle (FA) & 146,486 & $3.71 \pm 1.33$ & 0.15 \\
Fore udder attachment (FUA) & 145,954 & $3.97 \pm 1.48$ & 0.29 \\
Rear udder height (RUH) & 147,882 & $3.82 \pm 1.54$ & 0.28 \\
Rear udder width (RUW) & 147,831 & $3.68 \pm 1.46$ & 0.23 \\
Udder cleft (UC) & 148,294 & $4.07 \pm 1.32$ & 0.24 \\
Udder depth (UD) & 146,989 & $4.13 \pm 1.63$ & 0.28 \\
Front teat placement (FTP) & 146,708 & $3.60 \pm 1.35$ & 0.26 \\
Front teat length (FTL) & 144,530 & $4.06 \pm 1.53$ & 0.26 \\
\hline
\end{tabular}

* Holstein genetic evaluation report in Korea at the second half of 2006. 

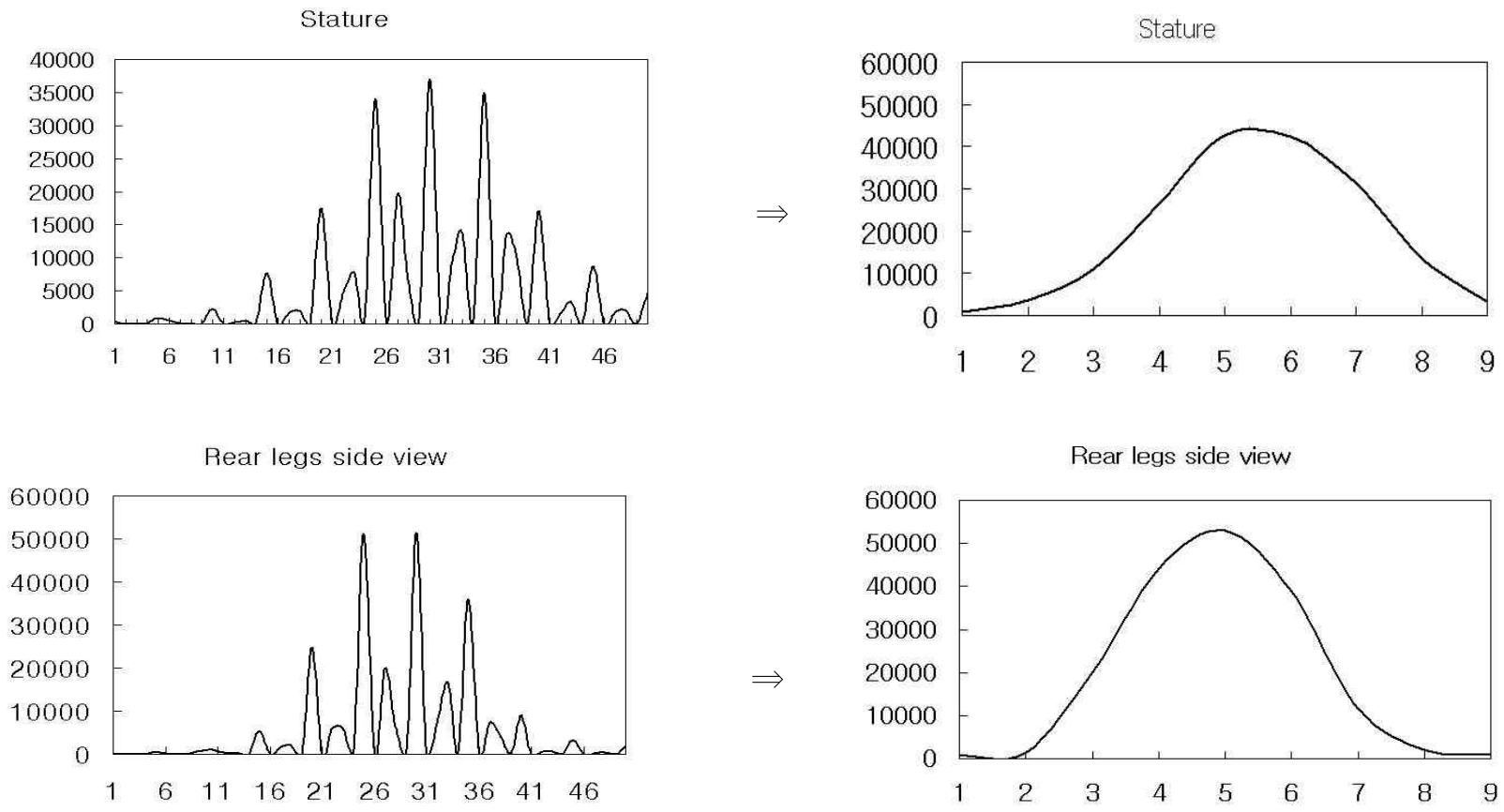

Fig. 1. Distribution of 9 class and 50 class data for linear type traits.

\section{2. 형질별 분산분석}

Table 3. Analysis of variance for linear traits and final scores by 50 class

\begin{tabular}{|c|c|c|c|c|c|c|c|}
\hline \multirow{2}{*}{ Source } & \multirow{2}{*}{$\mathrm{df}$} & \multicolumn{2}{|c|}{ ST } & \multicolumn{2}{|c|}{ STR } & \multicolumn{2}{|c|}{$\mathrm{BD}$} \\
\hline & & MS & $\mathrm{F}$ & MS & $\mathrm{F}$ & MS & $\mathrm{F}$ \\
\hline $\mathrm{Cla}^{1}$ & 3 & 103269.22 & 1928.74* & 16350.83 & 472.51* & 2622.67 & $69.59 *$ \\
\hline $\mathrm{Age}^{2}$ & 3 & 167998.41 & $3137.67 *$ & 230423.07 & $6658.78^{*}$ & 286128.65 & $7591.69 *$ \\
\hline \multirow[t]{2}{*}{ Stage $^{3}$} & 11 & 495.88 & $9.26^{*}$ & 1562.65 & $45.16^{*}$ & 1764.12 & $46.81^{*}$ \\
\hline & & \multicolumn{2}{|c|}{ DF } & \multicolumn{2}{|c|}{ RA } & \multicolumn{2}{|c|}{ TW } \\
\hline Cla. & 3 & 60566.54 & $1778.59 *$ & 644.21 & $9.91 *$ & 25822.74 & $664.72 *$ \\
\hline Age & 3 & 71078.19 & $2087.28 *$ & 846.42 & $13.02 *$ & 246397.57 & $6342.64 *$ \\
\hline \multirow[t]{2}{*}{ Stage } & 11 & 12442.39 & $365.38 *$ & 3718.57 & $57.19^{*}$ & 784.31 & $20.19^{*}$ \\
\hline & & \multicolumn{2}{|c|}{ RLSV } & \multicolumn{2}{|c|}{ FA } & \multicolumn{2}{|c|}{ FUA } \\
\hline Cla. & 3 & 7488.36 & $191.14^{*}$ & 123214.32 & $2832.71 *$ & 100075.41 & $1652.46^{*}$ \\
\hline Age & 3 & 40443.90 & $1032.35^{*}$ & 51890.39 & $1192.96^{*}$ & 4389.23 & $72.48 *$ \\
\hline \multirow[t]{2}{*}{ Stage } & 11 & 582.66 & $14.87 *$ & 367.55 & $8.45^{*}$ & 1292.10 & $21.34 *$ \\
\hline & & \multicolumn{2}{|c|}{ RUH } & \multicolumn{2}{|c|}{ RUW } & \multicolumn{2}{|c|}{$\mathrm{UC}$} \\
\hline Cla. & 3 & 98160.23 & $1639.87 *$ & 80283.59 & $1798.60 *$ & 59437.41 & $1337.78^{*}$ \\
\hline Age & 3 & 6065.73 & $101.33^{*}$ & 121840.43 & $2729.60 *$ & 19678.60 & $442.92 *$ \\
\hline \multirow[t]{2}{*}{ Stage } & 11 & 17298.18 & $288.98 *$ & 18229.15 & $408.39^{*}$ & 3617.34 & $81.42 *$ \\
\hline & & \multicolumn{2}{|c|}{ UD } & \multicolumn{2}{|c|}{ FTP } & \multicolumn{2}{|c|}{ FTL } \\
\hline Cla. & 3 & 10554.15 & $196.96^{*}$ & 8602.26 & $166.80^{*}$ & 12996.47 & $205.40^{*}$ \\
\hline Age & 3 & 504054.16 & $9406.59 *$ & 3919.50 & $76.00 *$ & 67174.63 & $1061.64 *$ \\
\hline Stage & 11 & 6162.68 & $115.01 *$ & 5968.15 & $115.72 *$ & 2538.06 & $40.11 *$ \\
\hline
\end{tabular}

$\mathrm{MS}=$ mean square, $\mathrm{Cla}^{1}{ }^{1}=$ classifier, $\mathrm{Age}^{2}=$ age at classification, Stage $^{3}=$ lactation stage, ${ }^{*}=P<0.001$. 
Table 4. Analysis of variance for linear traits and final scores by 9 class

\begin{tabular}{|c|c|c|c|c|c|c|c|}
\hline \multirow{2}{*}{ Source } & \multirow{2}{*}{$\mathrm{df}$} & \multicolumn{2}{|c|}{ ST } & \multicolumn{2}{|c|}{ STR } & \multicolumn{2}{|c|}{$\mathrm{BD}$} \\
\hline & & MS & $\mathrm{F}$ & MS & $\mathrm{F}$ & MS & $\mathrm{F}$ \\
\hline Cla. & 3 & 3482.78 & $1724.18^{*}$ & 490.30 & $379.36^{*}$ & 102.04 & $70.34 *$ \\
\hline age & 3 & 6106.29 & $3022.98 *$ & 8290.68 & $6414.67 *$ & 10444.09 & 7199.24* \\
\hline \multirow[t]{2}{*}{ stage } & 11 & 15.57 & $7.71 *$ & 37.65 & $29.13 *$ & 57.03 & $39.31 *$ \\
\hline & & \multicolumn{2}{|c|}{ DF } & \multicolumn{2}{|c|}{ RA } & \multicolumn{2}{|c|}{ TW } \\
\hline Cla. & 3 & 1902.15 & $1363.61 *$ & 65.90 & $25.51^{*}$ & 968.65 & $638.49 *$ \\
\hline age & 3 & 2817.26 & $2019.63^{*}$ & 42.27 & $16.36^{*}$ & 9047.54 & $5963.77^{*}$ \\
\hline \multirow[t]{2}{*}{ stage } & 11 & 477.15 & $342.06^{*}$ & 152.37 & $58.98^{*}$ & 30.02 & $19.79 *$ \\
\hline & & \multicolumn{2}{|c|}{ RLSV } & \multicolumn{2}{|c|}{ FA } & \multicolumn{2}{|c|}{ FUA } \\
\hline Cla. & 3 & 229.04 & $137.97 *$ & 3943.13 & $2388.85^{*}$ & 3466.51 & $1615.21 *$ \\
\hline age & 3 & 1747.80 & $1052.87^{*}$ & 1726.50 & $1045.96^{*}$ & 40.28 & $18.77^{*}$ \\
\hline \multirow[t]{2}{*}{ stage } & 11 & 23.91 & $14.4^{*}$ & 11.37 & $6.89 *$ & 59.05 & $27.51 *$ \\
\hline & & \multicolumn{2}{|c|}{ RUH } & \multicolumn{2}{|c|}{ RUW } & \multicolumn{2}{|c|}{ UC } \\
\hline Cla. & 3 & 2926.36 & $1270.27^{*}$ & 2496.00 & $1460.84^{*}$ & 1972.15 & $1148.63 *$ \\
\hline age & 3 & 187.81 & $81.52 *$ & 4308.20 & $2521.47^{*}$ & 647.43 & $377.08 *$ \\
\hline \multirow[t]{2}{*}{ stage } & 11 & 649.76 & $282.05^{*}$ & 662.28 & $387.61 *$ & 115.16 & $67.08^{*}$ \\
\hline & & \multicolumn{2}{|c|}{ UD } & \multicolumn{2}{|c|}{ FTP } & \multicolumn{2}{|c|}{ FTL } \\
\hline Cla. & 3 & 527.83 & $259.25^{*}$ & 430.54 & $229.92 *$ & 681.59 & $295.71 *$ \\
\hline age & 3 & 17033.44 & $8366.32 *$ & 64.87 & $34.64 *$ & 2218.69 & $962.59 *$ \\
\hline stage & 11 & 205.59 & $100.98 *$ & 189.62 & $101.26^{*}$ & 73.96 & $32.09 *$ \\
\hline
\end{tabular}

MS $=$ mean square, Cla. $^{1}=$ classifier, Age $^{2}=$ age at classification, Stage $^{3}=$ lactation stage, ${ }^{*}=\mathrm{P}<0.001$.

50 단계의 형질별 점수집단과 변환한 9단계의 점수집단 들의 분산분석결과를 Table 3 과 Table 4에 제시하였다. 두 점수제의 모든 선형형질들이 심사자, 심사시 연령, 비유단 계의 환경요인과 고도의 유의성 $(\mathrm{p}<0.001)$ 을 보이는 것으 로 나타났다. 심사자에 따라 변이가 크게 나타나는 형질 은 발굽기울기 (FA), 키 (ST), 앞유방의 붙음성 (FUA), 예각 성 $(\mathrm{DF})$ 의 순이었으며, 변이 차이가 적게 나타나는 형질은
엉덩이기울기 (RA), 체심 (BD), 유방의 깊이 (UD)의 순이었 다. 그리고, 심사시의 연령에 의해 영향을 가장 많이 받는 형질은 유방의 깊이 (UD)였는데 이는 송 등 (2002)의 연구 보고와 같은 결과였다. 반면 가장 적게 영향을 받는 형질 은 엉덩이 기울기 (RA)였다. 또한, 비유단계에 따라 영향 을 많이 받는 형질은 뒷유방의 너비 (RUW)와 예각성 (DF) 이었으며 이는 이 등(2006)의 연구보고와 같은 결과였다.

Table 5. Least square means and standard errors for linear traits score according to classifier by 9 class

\begin{tabular}{|c|c|c|c|c|c|c|c|c|}
\hline Trait & ST & STR & $\mathrm{BD}$ & DF & RA & TW & RLSV & \\
\hline Cla.* & $\mathrm{LSM} \pm \mathrm{SE}$ & $\mathrm{LSM} \pm \mathrm{SE}$ & $\mathrm{LSM} \pm \mathrm{SE}$ & $\mathrm{LSM} \pm \mathrm{SE}$ & $\mathrm{LSM} \pm \mathrm{SE}$ & $\mathrm{LSM} \pm \mathrm{SE}$ & $\mathrm{LSM} \pm \mathrm{SE}$ & \\
\hline 1 & $5.23 \pm 0.03$ & $3.14 \pm 0.02$ & $3.39 \pm 0.02$ & $3.21 \pm 0.02$ & $4.21 \pm 0.03$ & $3.54 \pm 0.02$ & $4.61 \pm 0.03$ & \\
\hline 2 & $5.50 \pm 0.03$ & $3.44 \pm 0.02$ & $3.34 \pm 0.03$ & $3.71 \pm 0.02$ & $4.11 \pm 0.03$ & $3.91 \pm 0.03$ & $4.82 \pm 0.03$ & \\
\hline 3 & $5.27 \pm 0.03$ & $3.19 \pm 0.02$ & $3.22 \pm 0.03$ & $2.89 \pm 0.02$ & $4.19 \pm 0.03$ & $3.42 \pm 0.03$ & $4.58 \pm 0.03$ & \\
\hline 4 & $4.31 \pm 0.03$ & $3.05 \pm 0.02$ & $3.26 \pm 0.03$ & $3.23 \pm 0.02$ & $4.09 \pm 0.03$ & $3.42 \pm 0.03$ & $4.61 \pm 0.03$ & \\
\hline Trait & FA & FUA & RUH & RUW & UC & UD & FTP & FTL \\
\hline Cla.* & $\mathrm{LSM} \pm \mathrm{SE}$ & $\mathrm{LSM} \pm \mathrm{SE}$ & $\mathrm{LSM} \pm \mathrm{SE}$ & $\mathrm{LSM} \pm \mathrm{SE}$ & $\mathrm{LSM} \pm \mathrm{SE}$ & $\mathrm{LSM} \pm \mathrm{SE}$ & $\mathrm{LSM} \pm \mathrm{SE}$ & $\mathrm{LSM} \pm \mathrm{SE}$ \\
\hline 1 & $3.77 \pm 0.03$ & $3.43 \pm 0.03$ & $3.23 \pm 0.03$ & $2.60 \pm 0.03$ & $4.16 \pm 0.03$ & $4.81 \pm 0.03$ & $3.70 \pm 0.03$ & $4.01 \pm 0.03$ \\
\hline 2 & $4.46 \pm 0.03$ & $4.09 \pm 0.03$ & $4.06 \pm 0.03$ & $3.22 \pm 0.03$ & $3.81 \pm 0.03$ & $4.50 \pm 0.03$ & $3.46 \pm 0.03$ & $3.79 \pm 0.03$ \\
\hline 3 & $3.69 \pm 0.03$ & $3.86 \pm 0.03$ & $3.56 \pm 0.03$ & $3.00 \pm 0.03$ & $3.83 \pm 0.03$ & $4.77 \pm 0.03$ & $3.79 \pm 0.03$ & $3.75 \pm 0.03$ \\
\hline 4 & $3.26 \pm 0.03$ & $4.44 \pm 0.03$ & $3.40 \pm 0.03$ & $3.40 \pm 0.03$ & $4.65 \pm 0.03$ & $4.90 \pm 0.03$ & $3.81 \pm 0.03$ & $3.53 \pm 0.03$ \\
\hline
\end{tabular}

$*$ Cla. $=$ Classifier, LSM $=$ Least square mean. 


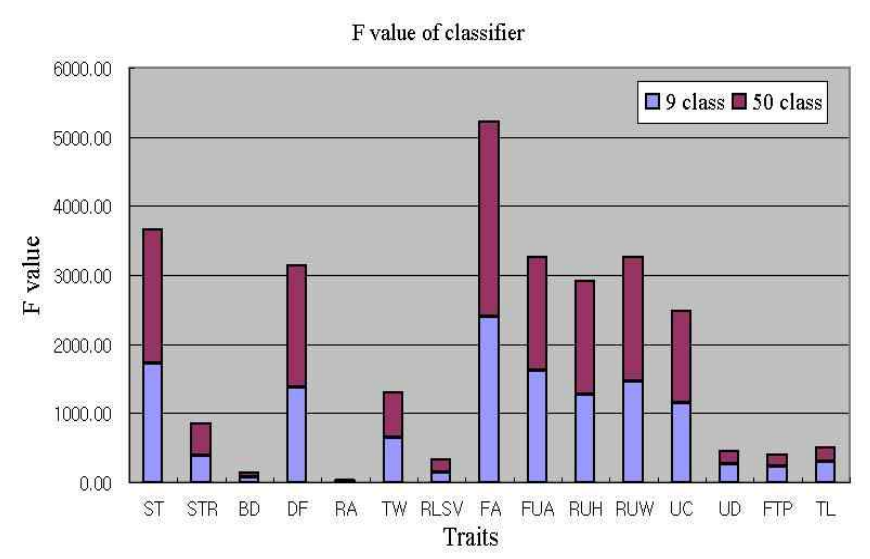

Fig. 2. F value for linear type traits of 9 class and 50 class according to classifier.

ST : stature, STR : strength, BD : body depth, DF : dairy form, RA : rump angle, TW : thurl width, RLSV : rear legs side view, FA : foot angel, RUH : rear udder height, RUW : rear udder width, UC : udder cleft, UD : udder depth, FTP : front teat placement, FTL : front teat length.

반면 가장 영향을 적게 받는 형질은 발굽기울기 (FA) 형질 이었다. 이는 체형형질들이 연령과 비유단계에 유의차를 보였다는 것을 보고한 이 등 (1994), 이 등 (2007), Hayes와 $\mathrm{Mao}$ (1987)의 연구보고와 같은 결과였다.

\section{3. 최소자승평균추정}

Table 5는 점수제 변환 후에도 심사자의 효과가 크게 작용하는 것으로 분석되어 심사자에 따른 추가분석을 실 시한 최소자승평균 추정값(Least squares mean, LSM)을 나 타낸 표이다. 체심 $(\mathrm{BD})$, 엉덩이 기울기 (RA), 앞유두의 길 이 (FTL)의 경우 1 번째 심사자에서 높게 나타났고, 키 (ST), 강건성 (STR)과 엉덩이나 발굽쪽의 체형형질에 대해 서는 2번째 심사자에서 높게 분석되었다. 예각성 (Angularity/ $\mathrm{DF})$ 은 3 번째 심사자에서만 높게 나타났으며, 특히 유방관 련형질들은 4 번째 심사자의 경우에 가장 높은 점수를 주 는 것으로 나타났다.

Fig. 2에는 형질별 9단계 집단과 50단계 집단의 심사자 에 따른 $\mathrm{F}$ 값의 차이를 나타내었다. 그림에서와 같이 두
집단은 거의 유사한 분산의 비를 보였다. 하지만 발굽기 울기(FA)는 50 단계의 점수를 9 단계로 전환을 해도 다른 형질들에 비해 상대적으로 심사자에 따른 차이가 많이 존 재한다는 것으로 나타났다.

Table 6은 9단계로 전환시킨 자료 집단과 50단계 집단 의 자료들에 대한 심사자, 심사시연령, 비유단계에 따른 상관분석을 실시한 결과이다. 분석결과 모든 형질에서 심 사자, 심사시의 연령, 비유단계에 따른 상관계수가 0.97 0.99 의 범위를 보여 세분화된 집단단계에서 그 단계를 줄 여도 점수제간에 거의 변화가 없는 것으로 나타났다.

\section{IV. 고 찰}

2009년 기준 농가의 평균 도태 산차는 2.5산으로 이는 우군 내에서 경제적 수명을 채우지 못하고 도태되는 소가 많다고 할 수 있다. 경제적 산차에 도달하기 위해서는 4 산 이상까지 갈 수 있도록 번식, 사양, 환경 등이 조화를 이루어야 한다. 후대검정우들의 선형심사를 정확하게 심 사해야 할 필요도 있지만 집단의 변화가 거의 없으며 종 모우의 순위변화가 없고 집단간의 상관관계가 높게 나타 나므로 연구의 목적에 부합하게 정규분포에 가까운 분포 와 같이 폭넓게 평가하고 유전평가의 정확도를 높이는 방 법으로 전환해야 할 것이다. 결론적으로 정확한 선형심사 를 바탕으로 젖소에 대한 유전능력평가의 정확도를 향상 시키기 위해서는 현행의 50 단계의 선형심사 점수제에서 국제표준 평가방법인 9단계로의 변환을 고려해야 할 것으 로 보인다. 본 연구결과에서와 같이 심사자에 따라 평균 점수 및 편차가 다른 것으로 나타나 9단계로의 변경은 가 능하지만 사전에 다른 효과들과 함께 육종가의 추정시에 모형내 보정이나 사전 보정을 해야 할 것으로 판단되었다 (Veerkamp 등, 2002). 즉, 단기간의 변경보다는 심사자, 연 령 그리고, 비유단계와 같은 환경적요인 등에 대한 다양 한 검토와 충분한 검정기간을 거쳐 적합성여부를 결정해 야 할 것이다. 그리고, 심사자에 따른 평가점수의 편차를 줄이기 위해 정기적인 교육이 반드시 필요하며, 이를 통 하여 심사척도의 표준화가 이루어진다면 점수제 변경 후 에도 심사의 정확도가 크게 향상될 것으로 사료되었다. 또한, 선형형질에 대한 점수제의 변경이나 심사자에 따른 유전모수 추정과 같은 연구가 전무하므로 이에 대한 연구 가 추가적으로 이루어져야 할 것으로 사료된다.

Table 6. Correlation analysis for linear type traits according to environmental factors between 9 class and 50 class

\begin{tabular}{|c|c|c|c|c|c|c|c|c|c|c|c|c|c|c|c|}
\hline Traits & ST & STR & $\mathrm{BD}$ & DF & RA & TW & RLSV & FA & FUA & RUH & RUW & UC & UD & FTP & TL \\
\hline Classifier & 0.98 & 0.98 & 0.98 & 0.98 & 0.99 & 0.98 & 0.98 & 0.98 & 0.99 & 0.99 & 0.98 & 0.98 & 0.99 & 0.99 & 0.99 \\
\hline Age* & 0.98 & 0.97 & 0.98 & 0.98 & 0.97 & 0.98 & 0.98 & 0.98 & 0.99 & 0.99 & 0.98 & 0.98 & 0.98 & 0.99 & 0.99 \\
\hline Lactation stage & 0.98 & 0.98 & 0.98 & 0.98 & 0.97 & 0.98 & 0.98 & 0.98 & 0.99 & 0.99 & 0.98 & 0.98 & 0.98 & 0.99 & 0.99 \\
\hline
\end{tabular}

\footnotetext{
* Age at classification.
} 


\section{V. 요 약}

국제간의 젖소유전능력평가 점수의 비교를 통한 우리의 우수유전자원의 교류와 경쟁력 향상을 위해서는 검정기준, 평가방법과 모델 등에 많은 보완이 필요하다. 따라서, 본 연구는 현재 국내의 50 단계의 심사점수를 낙농선진국에서 채택하고 있는 9점제로의 변환을 통해 국제기준을 국내 현실에 맞게 적용하기 위해 실시했다. 분석에는 한국 종 축개량협회(KAIA)의 젖소에 대한 혈통기록 및 2001에서 2006년도 사이에 실시된 체형 측정 기록 중 최종점수와 15 개 체형형질에 대해 초산차의 기록을 갖는 32,487 두의 암소집단의 선형심사기록 자료가 이용되었다. 9점제로 변 경한 집단이 더욱 정규성을 띄는 분포 특성을 나타내었다. 상관분석결과에서도 모든 형질에서 50 점제와 9점제 심사 점수간에 0.98 이상의 상관계수를 나타내었다. 따라서, 50 점제에서 9점제로의 변경이 가능할 것으로 판단된다. 하 지만, 9점제로의 변환 후 모든 형질에서 심사자에 따라 고도의 유의성을 보였고 $(\mathrm{P}<0.001)$, 점수제간 $\mathrm{F}$ 값은 발굽기 울기와 앞유방의 붙음성은 심사자간 변이가 비교적 높게 나타났다. 이것은 9점제로의 변환 후에도 심사자의 주관 적인 요소가 점수에 영향을 미치는 것을 의미한다. 따라 서, 선형형질 점수제 변환은 환경효과에 대한 다양한 분 석을 통하여 적합성 여부를 결정해야 할 것이다.

\section{VI. 인 용 문 헌}

1. Boelling, D. and Pollott, G. E. 1998. Locomotion, lameness, hoof and leg traits in cattle: II. Genetic relationships and breeding value. Livest. Prod. Sci. 54:205-215.

2. Brotherstone, S. and Hill, W. G. 1991. Dairy herd life in relation to linear type traits and production. e. Genetic analyses for pedigree and non-pedigree cows. Anim. Prod. 53:298-297.

3. Dadati, E., Kennedy, B. W. and Burnside, E. B. 1985. Relationships between conformation and reproduction in Holstein cows: type and calving performance. J. Dairy Sci. 68:2639-2645

4. De jong, G. and Lansbergen, L. 1996. Udder health index: selection for mastitis resistance. Proceedings of the International workshop on genetic improvement of functional traits in cattle, Gembloux, Belgium, January 1996. INTERBULL Bull. 12:42-47.

5. Hayes, A. E. and Mao, I. L. 1987. Effect of parity, age and stage of lactation at classification on linear type scores of Holstein cattle. J. Dairy Sci. 70:1898.

6. Hewitt, D. 2000. Type harmonisation working group-report of
World Holstein Friesian Federation 5th Classifiers Workshop. Pages 172-177 in 10th World Holstein-Friesian Conference, Sydney.

7. Holstein Association USA. 2005. http//www.holsteinusa.com/ Dec. 12, 2005 accessed.

8. Koenen, E. P. C. and Groen, A. F. 1998. Genetic evaluation of body weight of lactating Holstein heifers using body measurements and conformation traits. J. Dairy Sci. 81:17091713.

9. Setati, M. M., Norris, D., Banga, C. B. and Benyi, K. 2004. Relationships between Longevity and Linear Type Traits in Holstein Cattle Population of Southern Africa. Tropical Animal Health and Production, 36(8):807-814.

10. Thompson, J. R., Freeman, A. E., Wilson, D. J., Chapin, C. A., Breger, P. J. and Kuck, A. 1981. Evaluation of a Linear type program in Holsteins.

11. Tomas, C. L., Vinson, W. E., Pearson, R. E., Dicknson, F. N. and Johnson, L. P. 1984. Relationships between linear type scores, objective type measures, and indicators of mastitis. J. Dairy Sci. 67:1281-1292.

12. Neuenschwander, T., Kadarmideem, H. N., Wegmann, S. and de Haas, Y. 2005. Genetics of Parity-Dependant Production Increase and its Relationship with Health, Fertility, Longevity, and Conformation in Swiss Holsteins. J. Dairy. Sci. 88:15401551.

13. Tsuruta, S., Misztal, I. and Lawlor, T. J. 2005. Changing Definition of Productive Life in US Holsteins : Effection Genetic Correlations. J. Dairy Sci. 88:1156-1165.

14. Vacek, M., Stipkova, M., Nemcova, E. and Bouska, J. 2006. Relationships between conformation traits and longevity of Holstein cows in the CzechRepublic Czech. J. Anim. Sci. 51(8):327-333.

15. Vollema, A. R. and Groen, A. F. 1997. Genetic correlations between longevity and conformation traits in an upgrading dairy cattle population. J. Dairy Sci. 80:3006-3014.

16. Veerkamp, R. F. and Brotherstone, S. 1997. Genetic correlations between linear type traits, food intake, live weight and condition score in Holstein Friesian dairy cattle. Anim. Sci. 64:358-392

17. Veerkamp, R. F., Gerritsen, C. L. M., Koenen, E. P. C., Hamoen, A. and Ee Jong, G. 2002. J. Dairy Sci. 85:976-983.

18. Weigel, K. A., Lawlor, T. J., JR., Vanraden, P. M. and Wiggans, G. R. 1998. Use of Linear Type and Production Data to Supplement Early Predicted Transmitting Abilities for Productive Life. J. Dairy Sci. 81:2040-2044.

19. 송치은, 상병찬, 도창희. 2002. 국내 홀스타인 젖소의 선형심 
사에 대한 보정계수 개발. 한국동물자원과학회지. 44(1):1-12.

20. 이기환. 2008. Holstein종 젖소의 선형형질에 대한 유전모수추 정에 관한 연구. 충남대학교 석사학위논문.

21. 이광전, 강민식, 조광현, 강민구, 이상구. 1994. 체형 형질에 대한 보정계수 개발. 한축지. 36(6):574-583.

22. 이득환, 김은길. 2006. Holstein 젖소의 선형심사형질과 등급 형질에 대한 환경효과 분석. 한국동물자원과학회지. 48(6):
767-776.

23. (사)가축개량사업국. 2002. 유용우 생애 생산성 향상 기술. 일 본

24. 농촌진흥청 축산과학원. 2007. 2006년 하반기 젖소 유전능력 평가 보고서 II.

(접수일자 : 2008. 8. 7. / 수정일자 : 2009. 3. 26. /

채택일자 : 2009. 4. 9.) 